\title{
Sustained use of a tool for lifestyle intervention implemented in primary health care: a 2-year follow-up
}

Siw Carlfjord, Malou Lindberg and Agneta Andersson

\section{Linköping University Post Print}

\section{Tweet}

N.B.: When citing this work, cite the original article.

This is the pre-reviewed version of the following article:

Siw Carlfjord, Malou Lindberg and Agneta Andersson, Sustained use of a tool for lifestyle intervention implemented in primary health care: a 2-year follow-up, 2013, Journal of Evaluation In Clinical Practice, (19), 2, 327-334.

which has been published in final form at:

http://dx.doi.org/10.1111/j.1365-2753.2012.01827.x

Copyright: Wiley-Blackwell

http://eu.wiley.com/WileyCDA/Brand/id-35.html 


\section{Sustained use of a tool for lifestyle intervention implemented in primary health care: a 2-year follow-up}

S. Carlfjord RPT, MPH, ${ }^{1}$ M. Lindberg RN, PhD, ${ }^{2,3}$ A. Andersson PhD ${ }^{2,4}$

${ }^{1} \mathrm{PhD}$ student, Department of Medical and Health Sciences, Linköping University, Linköping,

Sweden

${ }^{2}$ Research supervisor, R\&D Department of Local Health Care, County Council of

Östergötland, Linköping University, Linköping, Sweden

${ }^{3}$ Department of Medical and Health Sciences, Primary Care, Linköping University, Linköping,

Sweden

${ }^{4}$ Health Economist, Department of Medical and Health Sciences, Linköping University, Linköping, Sweden

Correspondence: Siw Carlfjord, Department of Medical and Health Sciences, Division of Community Medicine, Linköping University, SE-581 83 Linköping, Sweden.

E-mail: siw.carlfjord@liu.se

Tel.: +46(0)101031017 fax: +46(0)101031865.

Running title: Implementation sustainability

Keywords: primary health care, implementation, lifestyle, sustainability 


\section{Abstract}

Rational, aims and objectives Sustainability of new methods implemented in health care is one of the most central issues in addressing the gap between research and practice, but is seldom assessed in implementation studies. The aim of this study was to evaluate the implementation of a new tool for lifestyle intervention in primary health care $(\mathrm{PHC}) 2$ years after the introduction, and assess if the implementation strategy used influenced sustainability.

Method A computer-based lifestyle intervention tool (CLT) was introduced at six PHC units in Sweden in 2008, using two implementation strategies: explicit and implicit. The main difference between the strategies was a 4-week test period followed by a decision session, included in the explicit strategy. Evaluations were performed after 6, 9 and 24 months. After 24 months, the RE-AIM framework was applied to assess and compare outcome according to strategy.

Results A more positive outcome regarding Reach, Effectiveness, Adoption and Implementation in the explicit group could be almost completely attributed to one of the units. Maintenance was low and after 24 months, differences according to strategy were negligible.

Conclusion After 24 months the most positive outcomes regarding all RE-AIM dimensions were found in one of the units where the explicit strategy was used. The explicit strategy per se had some effect on the dimension Effectiveness, but was not associated with sustainability overall. Staff at the most successful unit earlier had positive expectations regarding the CLT and found it compatible with existing routines. 


\section{Introduction}

Primary health care (PHC) has an important task in addressing lifestyle issues that might influence health, and computer-based solutions have been shown to have the capacity to facilitate this $[1,2]$. To be effective, however, it is important that such methods are successfully implemented and that their use in practice is sustained over time. One of the most central issues in addressing the gap between research and practice is the sustainability of innovations [3]. Despite this, sustainability is seldom assessed in implementation studies, which are often focused on barriers to and facilitators for implementation [4-7]. Factors known to improve the results in a short-term perspective, such as the use of economic incentives (e.g. pay for performance), have not proved to be effective over time [8-10]. Research funding typically supports follow-up for only 1 or 2 years, making it difficult to assess the use of an innovation or an intervention from a longer-term perspective [6]. However, it has been suggested that an implementation process requires $2-4$ years, after which sustainability can be evaluated [11].

Studies on the factors associated with sustainability have shown that leadership and attitudes are important at the staff level; infrastructure and fit with goals and culture at the organizational level; and adaptability and evidence are two of the important factors at the process level [12]. In a study on the sustainability of health promotion interventions, variables independently associated with perceived sustainability were low cost or no cost, modification of interventions during implementation, a good intervention-provider fit, and the presence of a program champion who advocates continuation of the intervention [13].

The study described in this article was conducted in Sweden, where health care is publicly funded and provided by county councils, and is part of an intervention study with the aim of evaluating an implementation in PHC. In 2008, a computer-based lifestyle intervention tool (CLT) was introduced at six selected PHC units, i.e. health care centers with general practitioners (GPs) and other health care professionals, using two different implementation strategies: a theory-based explicit strategy and an implicit strategy, not based on theory [14].

The first evaluation, performed after 6 months, showed that a creative climate at baseline in combination with an explicit implementation strategy predicted a positive 
implementation outcome [15]. After 9 months, both a quantitative and a qualitative evaluation were performed, showing that one of the six units had a significantly higher proportion of patients referred to the CLT than any of the other units [16]. Staff at this unit expressed positive expectations, perceptions of the CLT being compatible with existing routines, and perceptions of the CLT having advantages compared with previous practice [16]. When the RE-AIM framework was used for evaluation after 9 months, the explicit implementation strategy was found to have a positive effect on implementation outcome [14].

This article presents the 24-month evaluation, comparing the strategies used for implementation, but also assessing differences between the units where the same strategy was used. The unit found earlier to have a significantly better outcome than the other units was used as a reference for part of the analysis. The RE-AIM framework, assessing the dimensions Reach, Effectiveness, Adoption, Implementation and Maintenance, was used for the evaluation [17]. The aim of the study was to evaluate the implementation 2 years after the introduction of a new tool in PHC and assess if the explicit strategy was associated with sustainability.

\section{Methods}

\section{Setting and study design}

Six PHC units, two from each of three county councils in the southeast of Sweden, volunteered to participate in the study. Unit size in terms of listed patients varied from approximately 6000 to 13,500 when the CLT was introduced in 2008. The follow-up evaluation described in this article was performed 24 months after the initiation of patient referral to the CLT. Only staff members at the six participating units who took part in the former assessments $[14,15]$, were selected for this evaluation, as the study population was a closed cohort. Starting points for the participating PHC units were from April 2008 to October 2008, and follow-up measurements for the present study were performed from April to December 2010. 


\section{Implementation objective and strategies}

The CLT consists of a touch-screen computer equipped with a lifestyle assessment on alcohol consumption and physical activity habits, and a printer. Patients who perform the assessment receive immediate written feedback placing them in one of three categories, regarding alcohol (low risk, increased risk or hazardous consumption) and regarding physical activity (active, insufficiently active or inactive). Tailored advice is provided in a few statements, based on their answers. The CLT is described in detail in Carlfjord et al. [18].

Two different strategies, explicit and implicit, were used to introduce the CLT. The explicit implementation strategy began with an information session with a change agent from the research team visiting the unit. This first staff meeting was followed by a 4-week period during which staff members had the opportunity to perform the lifestyle assessment and become familiar with the CLT. After the test period, the change agent visited the unit again; there was a discussion about the tool before mutual agreement to incorporate it as a working method (or not) was made. The explicit strategy was developed using Rogers' theories about the innovation-decision process, including knowledge (the information session), persuasion (the test period), decision (the decision session), and implementation [19]. After the second meeting, the CLT was made available to patients and referral to the CLT was encouraged. The implicit, not theory-based, implementation strategy included a similar information session at the unit by a change agent from the research team. Immediately after that session, the CLT was installed and made available to patients. Staff members were given instructions about the opportunity to refer their patients to the CLT, but no further dialogue was encouraged.

One unit within each county council was assigned anonymously to the explicit strategy, the other to the implicit strategy. Units where the explicit strategy was used are referred to here as explicit units and units where the implicit strategy are called implicit units. The research team provided monthly feedback about the number of assessments performed, the proportion of patients in each category and reported on referrals to the manager and a liaison at each unit. 


\section{The RE-AIM framework}

The RE-AIM framework evaluates implementation in five dimensions: Reach (the target population), Effectiveness (impact on important outcomes), Adoption (settings willing to adopt), Implementation (consistency of delivery of intervention) and Maintenance (over time) [17]. For the present study, the framework was adapted so that Reach measured the proportion and frequency of staff members using the CLT as a working tool, Effectiveness measured the effect on staff members' attitudes and performance, Adoption was used to assess adoption at the setting level (proportion of patients being referred to the CLT), and Implementation measured fidelity to the original ideas of the innovation. Maintenance, not assessed after 9 months, was calculated from the Adoption rates over time for the 24-month evaluation. The concept of implementation in this article is used in two ways: as one of the dimensions of the RE-AIM framework, but also to describe the whole process of introducing and putting an innovation into practice.

\section{Data collection}

For the 9-month follow-up, a questionnaire with the aim of covering and evaluating the three RE-AIM dimensions, Reach, Effectiveness, and Implementation, was developed [14]. For the 24-month follow-up described in the present article, four new questions on Implementation and two questions on the manager's attitude towards discussing lifestyle issues and about responsibility to address lifestyle issues in health care, were added. Apart from background factors such as gender and profession, the 24-month questionnaire included ten statements about the computer-based tool which were answered using a 4point Likert type scale (agree, partly agree, partly disagree, disagree) and questions on referral to the computer and opinions about lifestyle issues. Questions were thoroughly examined and discussed by a group of experts in the research team until consensus was reached.

The questionnaire was sent by e-mail to staff at the participating units after the computers had been in operation, available to patients, for 24 months. In operation was interpreted as the time computers were functioning; in some units, the time period was prolonged to compensate for short periods of malfunction or holiday closures (one unit closed for 2 months during the study period). One hundred and seventeen questionnaires 
were distributed using the Web-based tool Publech ${ }^{\circledR}$ Survey 5.6, 62 to explicit units and 55 to implicit units. Reminders were sent to non-responders after 2 weeks and after 3 weeks. Questionnaires were answered anonymously and data were treated as confidential.

The outcome measurement for Adoption was the proportion of patients aged 18 years or older who visited the unit (eligible patients), performed the assessment, and stated they had been referred to the CLT by a staff member (referred patients (RP)). Data regarding RP were collected from the CLT database stored at each county council office. The number of eligible patients was obtained from county council registers. Data from county council registers were not available for Unit $\mathrm{V}$ and $\mathrm{VI}$ for the whole time period due to a change in the register's computer system. This was solved by calculating a mean number from available data, and estimating a mean for the period for which data were missing. Evaluation of Adoption was based on a 19-24 months period.

The Maintenance dimension was measured by comparing the proportion of RP over time (in 3-month periods). To assess the number of unique individuals visiting the units, three measurement periods were chosen: (1) after 0-9 months of operation; (2) months 10-18; (3) months 19-24. Within each 3-month period, a mean value for the number of eligible patients was calculated for the units and this value was compared with RP, registered monthly during the 24-month study period. All five RE-AIM dimensions were evaluated for differences between explicit and implicit units. Analysis of Unit I in comparison with all other units, and analysis of differences within the explicit and the implicit groups were also performed.

\section{Data analysis}

Statistical analyses were performed using the computer-based analysis program, Statistical Package for the Social Sciences (SPSS) version 19.0. Statistical significance was set at $p \leq 0.05$. Analysis of differences between groups according to ordinal data was performed using the Mann-Whitney $U$ or the Kruskal-Wallis tests, analysis of differences according to nominal data was performed using the chi-squared test, and differences in proportions between units were calculated as a risk ratio [20]. 


\section{Results}

Two explicit units, Units I and II (response rates 59\% and 62\%), and three implicit units, Units III-V (response rates $62 \%, 65 \%$, and $77 \%$ ), were included in the analysis. One unit (VI) had only four responders and was thus not included in the analysis. An analysis of the dropouts was performed and showed no significant differences in the proportions of each staff category or in gender among responders compared with the invited population.

In the explicit group, $22 \%$ of responders were GPs, $50 \%$ were nurses, $16 \%$ were nurse assistants, and $12 \%$ were allied health professionals. In the implicit group, the corresponding proportions were GPs $19 \%$, nurses $54 \%$, nurse assistants $16 \%$, and allied professionals $11 \%$. Responders in both groups had a mean age of 50 years (31-63 years in the explicit group, 31-65 years in the implicit group), and $84 \%$ in the explicit group and $89 \%$ in the implicit group were women. Of responders from the explicit units, $81 \%$ had been working in their profession >10 years; the corresponding figure for the implicit units was $89 \%$. At Unit I, 16\% of the responders were GPs, $42 \%$ were nurses, $21 \%$ were nurse assistants, and $21 \%$ were allied professionals. Mean age was 49 years, $84 \%$ were women, and $74 \%$ had been working in their profession $>10$ years.

\section{Reach}

The dimension Reach was measured as the proportion of staff referring patients to the CLT and frequency of referral. Data were obtained from the staff questionnaire. Response alternatives were daily, once a week, once a month or never. Explicit units reported daily or weekly referral to a higher degree than implicit units, but within the explicit group only staff at Unit I reported daily or weekly referral. When Unit I was compared with Units II-V, regardless of strategy, the difference was significant $(p=0.000)$.

\section{Effectiveness, Adoption, and Implementation}

Six of the statements/questions in the questionnaire concerned the dimension Effectiveness (Table 1). Comparing units according to strategy, responders at the explicit units were significantly more positive than responders at implicit units in four of the statements/questions, but an analysis at unit level showed significant differences between the two explicit units in two of these. For the statements "It feels good to refer to the CLT", 
and "I can represent the advice ...", no differences were found within the explicit group or within the implicit group, showing a possible difference according to strategy used. Staff at Unit I reported having read the advice provided by the CLT to a higher degree than staff at Unit II (Table 1).

To compare Adoption, a risk ratio (RR) for an eligible patient to be referred to the CLT was calculated. The RR to be referred to the CLT in an explicit unit compared with an implicit unit was 1.40 (confidence interval $(\mathrm{Cl})$ 0.83-2.33), showing no significant difference according to strategy. The RR to be referred to the CLT at Unit I compared with Units II-V was 3.15 (Cl $1.89-5.24)$.

Implementation was assessed with seven questions/statements. At explicit units, more positive answers were given in six of these, but all the differences could be attributed to differences between Unit I and Units II-V; within the group Units II-V, no differences were found (Table 2).

\section{Maintenance}

Maintenance was measured in terms of the proportion of RP in periods of 3 months from baseline to 24-month follow-up. The difference between these proportions at explicit and implicit units over time is illustrated in Fig. 1. The proportion of RP started at a higher level in the explicit units than in the implicit units. Over time, the proportions decreased and the difference between the explicit and implicit units almost disappeared. In the last 6 months, the proportions showed a tendency to stabilize at low levels. Proportions of RP over time at Unit I compared with Units II-V are illustrated in Fig. 2. The proportions of RP at Unit I were higher, but with decreasing differences over time, as proportions declined at Unit I. The mean number of eligible patients per month was 1264 at explicit units and 1674 at implicit units.

\section{Attitudes towards addressing lifestyle issues}

At explicit units, $28(87 \%)$ of the 32 respondents agreed to the statement that health care staff have a responsibility to ask patients about lifestyle issues, and 31 (99\%) agreed that the manager was positive about staff discussing lifestyle issues with patients. Corresponding numbers at implicit units were 27 (73\%) of 37 responders agreed that the staff have this 
responsibility, and 36 (97\%) perceived the manager as positive. No differences were found between Unit I and Units II-V for these items.

\section{Discussion}

The study was conducted to evaluate implementation 2 years after the introduction of a new tool for lifestyle intervention in PHC, and assess if the implementation strategy was associated with sustainability. The main finding was that apparent differences according to strategy could be attributed to a great extent to one specific unit presenting a better outcome than any of the other units. A possible difference between strategies was found only regarding two items in the dimension Effectiveness. Differences in Adoption, based on register data, detected after 9 months [14] had leveled out after 24 months. Maintenance revealed proportions of RP decreasing over time regardless of strategy, with a tendency to stabilize at low levels for the last 6 months of the study.

The explicit implementation strategy used in the study was based on Rogers' theories of the innovation-decision process, providing a test period to make staff try and reflect on the new tool, and a discussion session to increase involvement in the decision [19]. This strategy was supposed to facilitate the uptake of the innovation, but contained no specific activities aimed at promoting sustainability. However, as outcome differed according to strategy at the 9-month evaluation [14], it was considered important to compare explicit and implicit units also for the 24-month evaluation.

The factors at the process level that have been shown to be related to sustainability are evidence, adaptability (modification), low cost, and the presence of a program champion $[12,13,21]$. In the present study, modification was encouraged primarily at explicit units, as they were provided with an extra decision/discussion session focusing on how to use the tool. The other factors did not differ between strategies.

At the organizational level, the factors infrastructure and fit with goals and culture, have been found to influence sustainability $[12,13,21]$. These factors were not assessed in the present study and might have differed. A common goal in PHC, however, is to address lifestyle issues, and computer-based solutions have been found to be feasible to help accomplish this task [22-24]. When organizational climate was assessed at the units 
participating in the present study, the two explicit units had similar scores, both indicating innovativeness [15]. The difference in implementation outcome found between the two explicit units thus cannot be explained by a more creative climate. One implicit unit scored higher than the explicit units and two scored lower [15].

Attitudes among staff and leadership are other factors important for sustainability [12,21]. Attitudes to addressing lifestyle issues, when assessed in the present study, were that most staff at both the explicit and implicit units believed that it is their responsibility to address lifestyle issues. Regarding leadership, staff at all the units were confident that their manager was positive about staff discussing lifestyle issues with patients. When managers at the participating units were interviewed at the 9-month follow-up, they all seemed visionary about the implementation of the CLT, they perceived prevention as an important task, and felt a responsibility to provide preventive services [25]. Thus, both attitudes and leadership could have contributed to sustainability at all units.

In the present study, data regarding the RE-AIM dimensions Reach, Effectiveness and Implementation were based on staff reporting from the questionnaires. Regarding Reach, staff at Unit I reported referring to the CLT to a higher degree than staff at Units II-V. Register data on Adoption showed a corresponding difference. This congruence between staff-reported data and register data indicates that patients being referred to the CLT actually did perform the assessment, and that over-reporting referral as an effect of social desirability [26] was not affecting the results.

The Effectiveness dimension in the present study measures how the implementation of the CLT has influenced staff at the units, and showed differences between explicit and implicit units in two of the items assessed. These differences were also seen after 9 months [14]. Staff at explicit units seem to have been more influenced by the implementation of the $\mathrm{CLT}$, probably due to the test period and the involvement in the decision, an effect that is still present after 2 years. This could be explained in terms of research use typology, distinguishing between conceptual and instrumental research use [10]. Conceptual use includes a change in knowledge and attitudes, which probably occurred at explicit units, where staff have come to believe that referral to the CLT can be of benefit to patients. 
However, instrumental use, i.e. to incorporate the CLT in practice on a regular basis, is not obtained to the same degree.

Implementation, as a RE-AIM dimension, assesses if the innovation is used as intended. Regarding Implementation, almost all apparent differences according to strategy found in the present study could be attributed to differences between Unit I and Units II-V. Previous evaluations have shown that staff at Unit I had more positive expectations regarding the CLT than the other units; they also found it compatible and perceived that it had advantages compared with previous practice [16]. In the present study, staff at Unit I stated that the CLT facilitates work with lifestyle issues and that it is now an important part of addressing lifestyle issues. In contrast, staff at Units II-V to a higher degree stated that they see no need for the CLT. When Greenhalgh et al. [7] describe what they call a learning organization, they mention skills to acquire and transfer knowledge which then is used to modify behavior within the organization. These characteristics seem to be present at Unit I, which probably made the explicit strategy more effective at Unit I than at Unit II, where the same strategy was used. Trial, for example, was an important part of the explicit strategy. Staff members who tried the CLT received the printed advice, and as fewer staff members at Unit II than at Unit I stated that they did read the advice, this could indicate a lower proportion of staff who exploited the opportunity to try the CLT at Unit II.

Adoption, measured as the proportion of patients reporting staff referral to the CLT, was not higher at explicit units than at implicit units after 24 months. At Unit I, however, significantly more patients reported referral than at Units II-V, but also at Unit I the proportion of patients reporting referral was less than $1 \%$ of eligible patients. This must be considered a failure, even if it is known that when new technology is installed in an organization, about $70 \%$ of all change initiatives fail to survive [27].

Maintenance assesses how the innovation is used over time. Results regarding Maintenance are somewhat discouraging, because the referral rates decreased over time, and the differences between strategies that could be seen for the first months had disappeared during the last few months of the study period. This picture is also present when Unit I is compared with Units II-V. This shows that continued referral demands effort, and regardless of the strategy at introduction, continued implementation activities seems to 
be required, for example, by electing a program champion as suggested by O'Loughlin et al. [13] and Parrish et al. [21]. Other factors found to support long-term change when quality improvement in primary care has been studied are education and reinforcement [28]. These factors could also be facilitated by a program champion.

The nature of this study involves a number of limitations that must be considered when interpreting the results. Most of the data are self-reported by staff, and data from the CLT database regarding referral were registered only in cases when patients actually did perform the assessment. There was no reliable instrument to measure how many patients were referred but chose not to perform the assessment. Thus, referral rates might have been higher than what was registered. Another limitation is that the questionnaires were designed for the specific study. A group of experts from the research team thoroughly examined and discussed the questions until consensus was reached, to obtain face validity, but the questionnaires have not been tested for reliability [29].

The design of the study caused some difficulties in the use of data from county council registers. Patients visiting the units several times a month were not supposed to be referred to the CLT each time, which is why monthly registering of unique eligible patients could not be used. Instead, a mean number of eligible patients per month was calculated from the number of unique patients over a longer time period. Over the whole study period, this is thought to have had no or little impact.

Including both staff-reported data and register data was a strength in the study. The REAIM framework served as a tool to evaluate both types of data in a structured way, evaluating three of the dimensions based on staff-reported data, and two dimensions based on register data. The response rate for the staff questionnaire was fairly high, and the dropout analysis showed no differences between responders and the invited group.

\section{Conclusion}

After 24 months, the most positive outcomes regarding Reach, Effectiveness, Adoption Implementation, and Maintenance were found in one of the units where the explicit strategy was used. Explicit strategy per se had some effect on the dimension Effectiveness, but was not associated with sustainability overall. Staff at the most successful unit earlier had been 
found to have positive expectations regarding the CLT and to find it compatible with existing routines.

\section{Acknowledgments}

This work was supported by the Medical Research Council of Southeast Sweden (FORSS) and the Swedish Council for Working Life and Social Research (FAS). The authors declare that they have no competing interests. 


\section{References}

1. Glasgow, R. E., Bull, S. S., Piette, J. D., Steiner, J. F. (2004) Interactive behavior change technology. A partial solution to the competing demands of primary care. American Journal of Preventive Medicine, 27(2 Suppl), 80-87.

2. Kypri, K., Stephenson, S., Langley, J., Cashell-Smith, M., Saunders, J., Russell, D. (2005) Computerised screening for hazardous drinking in primary care. New Zealand Medical Journal, 118(1224), U1703.

3. Mendel, P., Meredith, L. S., Schoenbaum, M., Sherbourne, C. D., Wells, K. B. (2008) Interventtions in organizational and community context: a framework for building evidence on dissemination and implementation in health services research. Administration and Policy in Mental Health, 35(1-2), 21-37.

4. Johnson, M., Jackson, R., Guillaume, L., Meier, P., Goyder, E. (2010) Barriers and facilitators to implementing screening and brief intervention for alcohol misuse: a systematic review of qualitative evidence. Journal of Public Health (Oxford), 33(3), $412-421$.

5. Nilsson Kajermo, K., Boström, A-M., Thompson, D. S., Hutchinson, A. M., Estabrooks, C. A., Wallin, L. (2010) The BARRIERS scale - the barriers to research utilization scale: a systematic review. Implementation Science, 5, 32 doi:10.1186/1748-5908-5-32.

6. Davies, B., Edwards, N. (2009) Sustaining knowledge use. In Knowledge Translation in Health Care: Moving from Evidence to Practice. (eds S. Straus, J. Tetroe, I. D. Graham), pp. 165-173. Oxford: Wiley-Blackwell.

7. Greenhalgh, T., Robert, G., Bate, P., Macfarlane, F., Kyriakidou, O. (2005) Diffusion of Innovation in Health Service Organisations. A Systematic Literature Review. Oxford: BMJ Books.

8. Grossbart, S. R. (2006) What's the return? Assessing the effect of "pay-forperformance" initiatives on the quality of care. Medical Care Research and Review, 63(Suppl 1), 29S-48S. 
9. Petersen, L. A., Woodard, L. D., Urech, T., Daw, C., Sookanan, S. (2006) Does pay-forperformance improve the quality of health care? Annals of Internal Medicine, 145, 265-272.

10. Nutley, S., Walter, I., Davies, H. T. O. (2007) Using Evidence. How Research Can Inform Public Services. Bristol: Policy Press.

11. Fixsen, D. L., Naoom, S. F., Blasé, K. A., Friedman, R. M., Wallace, F. (2005) Implementation Research: A Synthesis of the Literature. Tampa, FL: University of South Florida, Louis de la Parte Florida Mental Health Institute.

12. National Health Services (NHS). (2011) Sustainability: ensuring continuity in improvement. Available at:

http://www.institute.nhs.uk/sustainability_model/general/welcome_to_sustainability.html (last accessed 15 April 2011).

13. O'Loughlin, J., Renaud, L., Richard, L., Sanchez Gomez, L., Paradis, G. (1998) Correlates of the sustainability of community-based heart health promotion interventions. Preventive Medicine, 27, 702-712.

14. Carlfjord, S., Andersson, A., Bendtsen, P., Nilsen, P., Lindberg, M. (2011) Applying the RE-AIM framework to evaluate two implementation strategies used to introduce a tool for lifestyle intervention in Swedish primary health care. Health Promotion International, doi:10.1093/heapro/dar016.

15. Carlfjord, S., Andersson, A., Nilsen, P., Bendtsen, P., Lindberg, M. (2010) The importance of organizational climate and implementation strategy at the introduction of a new working tool in primary health care. Journal of Evaluation in Clinical Practice, 16, 1326-1332.

16. Carlfjord, S., Lindberg, M., Bendtsen, P., Nilsen, P., Andersson, A. (2010) Key factors influencing adoption of an innovation in primary health care: a qualitative study based on implementation theory. BMC Family Practice, 11, 60. 
17. RE-AIM homepage. Applying the RE-AIM framework. Available at: http://www.reaim.org (last accessed 15 April 2011).

18. Carlfjord, S., Nilsen, P., Leijon, M., Andersson, A., Johansson, K., Bendtsen, P. (2009) Computerized lifestyle intervention in routine primary health care: evaluation of usage on provider and responder levels. Patient Education and Counseling, 75, 238243.

19. Rogers, E. M. (2003) Diffusion of Innovation. 5th edition. New York: Free Press.

20. Kirkwood, B. R., Sterne, J. A. C. (2003) Medical Statistics. Malden, MA: Blackwell Publishing.

21. Parrish, M. M., O’Malley, K., Adams, R. I., Adams, S. R., Coleman, E. A. (2009) Implementation of the care transitions intervention: sustainability and lessons learned. Professional Case Management, 6, 282-293.

22. WHO. (2008) The World Health Report 2008 - Primary Health Care (Now More Than Ever). Geneva: World Health Organization.

23. Dubey, V., Mathew, R., Iglar, K., Moineddin, R., Glazier, R. (2006) Improving preventive service delivery at adult complete health check-ups: the Preventive health Evidence-based Recommendation Form (PERFORM) cluster randomized controlled trial. BMC Family Practice, 7, 44 doi:10.1186/1471-2296-7-44.

24. Oenema, A., Brug, J., Dijkstra, A., de Weerdt, I., de Vries, H. (2008) Efficacy and use of an internet-delivered computer-tailored lifestyle intervention, targeting saturated fat intake, physical activity and smoking cessation: a randomized controlled trial. Annals of Behavioral Medicine, 35, 125-135.

25. Carlfjord, S., Andersson, A., Lindberg, M. (2011) Experiences of the implementation of a tool for lifestyle intervention in primary health care: a qualitative study among managers and professional groups. BMC Health Services Research, 11, 195. 
26. Paulhus, D. L. (1991) Measurement and control of response bias. In Measures of Personality and Social Psychological Attitudes (eds J. P. Robinson, P. R. Shaver, L. S. Wrightsman), pp. 17-59. San Diego, CA: Academic Press.

27. Beer, M., Nohria, N. (2000) Cracking the code of change. Harvard Business Review, $78,133-141$.

28. Wentworth, A. L., Fox, C. H., Kahn, L. S., Glaser, K., Cadzow, R. (2010) Two years after a quality improvement intervention for chronic kidney disease care in a primary care office. American Journal of Medical Quality, doi:10.1177/1062860610381916.

29. Streiner, D. L., Norman, G. R. (2008) Health Measurement Scales. A Practical Guide to Their Development and Use. 4th edition. New York: Oxford University Press. 
Figure 1 Proportion of patients (age $\geq 18$ years), who performed the assessment and reported referral by staff. Outcome for the explicit and implicit strategies measured on a 3-month basis.

Figure 2 Proportion of patients (age $\geq 18$ years), who performed the assessment and reported referral by staff. Outcome for Unit I and Units II-V, measured on a 3-month basis. 
Table 1. Responses to questions concerning Effectiveness: responses at each unit and comparison between strategies, within strategies, and between Unit I and Units II-V

\begin{tabular}{|c|c|c|c|c|c|c|c|c|c|c|}
\hline \multirow[b]{2}{*}{ Statement/question } & \multicolumn{2}{|c|}{ Explicit units } & \multicolumn{3}{|c|}{ Implicit units } & \multicolumn{5}{|l|}{ p-values } \\
\hline & I & II & III & IV & $\mathrm{V}$ & $\begin{array}{l}\text { Explicit vs } \\
\text { implicit }\end{array}$ & $\begin{array}{l}\text { Within explicit } \\
\text { group }\end{array}$ & $\begin{array}{l}\text { Within implicit } \\
\text { group }\end{array}$ & $\begin{array}{l}\text { Unit I vs } \\
\text { Units II-V }\end{array}$ & $\begin{array}{l}\text { Within Units } \\
\text { II-V }\end{array}$ \\
\hline \multicolumn{6}{|c|}{ 1. Using the CLT is well supported amongst staff } & $0.013^{\mathrm{a}}$ & $0.001^{\mathrm{a}}$ & $0.069^{b}$ & $0.000^{\mathrm{a}}$ & $0.000^{b}$ \\
\hline Agree & 8 & 0 & 2 & 1 & 0 & & & & & \\
\hline Partly agree & 10 & 3 & 4 & 4 & 3 & & & & & \\
\hline Partly disagree & 1 & 7 & 5 & 8 & 2 & & & & & \\
\hline Disagree & 0 & 2 & 0 & 1 & 5 & & & & & \\
\hline Total $(n)$ & 19 & 12 & 11 & 14 & 10 & & & & & \\
\hline \multicolumn{6}{|c|}{ 2. It is my opinion that this health care center prioritizes discussion of lifestyle issues with patients } & $0.358^{\mathrm{a}}$ & $0.866^{\mathrm{a}}$ & $0.061^{\mathrm{b}}$ & $0.325^{\mathrm{a}}$ & $0.101^{\mathrm{b}}$ \\
\hline Agree & 0 & 0 & 0 & 0 & 0 & & & & & \\
\hline Partly agree & 1 & 2 & 0 & 3 & 0 & & & & & \\
\hline Partly disagree & 11 & 6 & 6 & 11 & 8 & & & & & \\
\hline Disagree & 7 & 5 & 5 & 2 & 2 & & & & & \\
\hline Total $(n)$ & 19 & 13 & 11 & 16 & 10 & & & & & \\
\hline \multicolumn{6}{|c|}{ 3. It feels good/would feel good to refer patients to the CLT } & $0.000^{\mathrm{a}}$ & $0.120^{\mathrm{a}}$ & $0.001^{\mathrm{b}}$ & $0.000^{\mathrm{a}}$ & $0.000^{\mathrm{b}}$ \\
\hline Agree & 9 & 0 & 1 & 1 & 0 & & & & & \\
\hline Partly agree & 10 & 7 & 7 & 3 & 6 & & & & & \\
\hline
\end{tabular}




\begin{tabular}{|c|c|c|c|c|c|c|c|c|c|c|}
\hline Partly disagree & 0 & 4 & 2 & 8 & 2 & & & & & \\
\hline Disagree & 0 & 0 & 1 & 2 & 2 & & & & & \\
\hline Total & 19 & 11 & 11 & 14 & 10 & & & & & \\
\hline \multicolumn{6}{|c|}{ 4. It is my judgment that it is possible to influence patients' lifestyles with the aid of the CLT } & $0.001^{\mathrm{a}}$ & $0.018^{\mathrm{a}}$ & $0.207^{\mathrm{b}}$ & $0.000^{\mathrm{a}}$ & $0.000^{\mathrm{b}}$ \\
\hline Agree & 6 & 0 & 1 & 1 & 0 & & & & & \\
\hline Partly agree & 13 & 7 & 7 & 3 & 6 & & & & & \\
\hline Partly disagree & 0 & 4 & 2 & 8 & 2 & & & & & \\
\hline Disagree & 0 & 0 & 1 & 2 & 2 & & & & & \\
\hline Total & 19 & 11 & 11 & 14 & 10 & & & & & \\
\hline \multicolumn{6}{|c|}{ 5a. I have read the advice provided by the CLT } & $0.816^{\mathrm{c}}$ & $0.005^{\mathrm{c}}$ & $0.064^{\mathrm{c}}$ & $0.002^{\mathrm{c}}$ & $0.002^{\mathrm{c}}$ \\
\hline Yes & 19 & 7 & 9 & 12 & 10 & & & & & \\
\hline No & 0 & 4 & 2 & 2 & 0 & & & & & \\
\hline Total & 19 & 11 & 11 & 14 & 10 & & & & & \\
\hline \multicolumn{6}{|c|}{ 5b. I feel I can represent the advice provided by the CLT ${ }^{d}$} & $0.001^{\mathrm{a}}$ & $0.497^{\mathrm{a}}$ & $0.064^{\mathrm{b}}$ & $0.002^{\mathrm{a}}$ & $0.002^{\mathrm{b}}$ \\
\hline Agree & 9 & 2 & 0 & 0 & 2 & & & & & \\
\hline Partly agree & 10 & 5 & 9 & 10 & 8 & & & & & \\
\hline Partly disagree & 0 & 0 & 0 & 2 & 0 & & & & & \\
\hline Disagree & 0 & 0 & 0 & 0 & 0 & & & & & \\
\hline \multirow[t]{2}{*}{ Total } & 19 & 7 & & & & & & & & \\
\hline & & & & & & $0.234^{\mathrm{a}}$ & $0.427^{\mathrm{a}}$ & $0.965^{\mathrm{b}}$ & $0.131^{\mathrm{a}}$ & $0.504^{\mathrm{b}}$ \\
\hline
\end{tabular}


compared with before its introduction?

Much more now

2

Some more now

As often

Some more before

Much more before

$\begin{array}{lllll}2 & 0 & 0 & 1 & 0 \\ 7 & 2 & 3 & 1 & 1 \\ 7 & 11 & 6 & 13 & 9 \\ 3 & 0 & 1 & 0 & 0 \\ 0 & 0 & 1 & 0 & 0\end{array}$

${ }^{a}$ Mann-Whitney $U$ test.

${ }^{b}$ Kruskal-Wallis test.

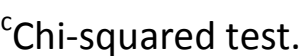

${ }^{d}$ Only responders who stated they had read the advice are included in the calculation. 
Table 2. Responses to the questions on Implementation: responses at each unit and comparison between strategies, within strategies, and between Unit I and Units II-V

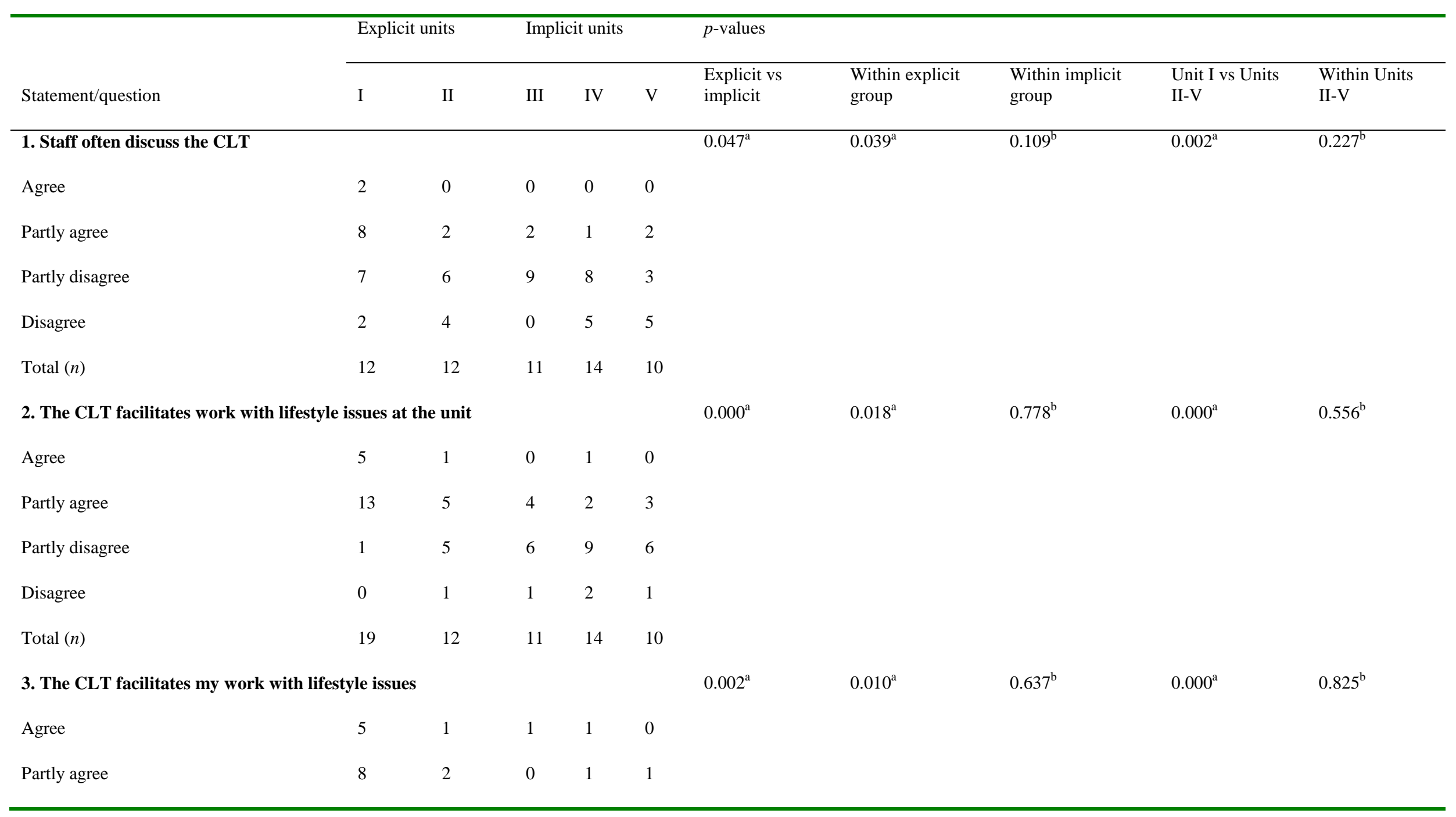




\begin{tabular}{|c|c|c|c|c|c|c|c|c|c|c|}
\hline Partly disagree & 6 & 5 & 7 & 9 & 5 & & & & & \\
\hline Disagree & 0 & 4 & 3 & 3 & 4 & & & & & \\
\hline Total $(n)$ & 12 & 19 & 11 & 14 & 10 & & & & & \\
\hline $\begin{array}{l}\text { 4. The CLT is today an impo } \\
\text { unit }\end{array}$ & work & ith li & issu & t our & & $0.000^{\mathrm{a}}$ & $0.000^{\mathrm{a}}$ & $0.064^{\mathrm{b}}$ & $0.000^{\mathrm{a}}$ & $0.085^{\mathrm{b}}$ \\
\hline Agree & 8 & 0 & 0 & 1 & 0 & & & & & \\
\hline Partly agree & 10 & 1 & 3 & 2 & 1 & & & & & \\
\hline Partly disagree & 1 & 9 & 7 & 8 & 3 & & & & & \\
\hline Disagree & 0 & 1 & 1 & 3 & 6 & & & & & \\
\hline Total (n) & 19 & 11 & 11 & 14 & 10 & & & & & \\
\hline 5. I see no need for the CLT & & & & & & $0.008^{\mathrm{a}}$ & $0.016^{\mathrm{a}}$ & $0.408^{\mathrm{b}}$ & $0.000^{\mathrm{a}}$ & $0.605^{\mathrm{b}}$ \\
\hline Agree & 1 & 0 & 0 & 1 & 0 & & & & & \\
\hline Partly agree & 0 & 3 & 2 & 5 & 2 & & & & & \\
\hline Partly disagree & 5 & 6 & 7 & 6 & 6 & & & & & \\
\hline Disagree & 13 & 2 & 2 & 2 & 2 & & & & & \\
\hline Total $(n)$ & 19 & 11 & 11 & 14 & 10 & & & & & \\
\hline $\begin{array}{l}\text { 6. Approximately what propc } \\
\text { based tool? }^{d}\end{array}$ & pati & o yo & to tl & omp & & $0.030^{\mathrm{C}}$ & $0.091^{\mathrm{c}}$ & $0.210^{\mathrm{C}}$ & $0.002^{\mathrm{C}}$ & $0.372^{\mathrm{C}}$ \\
\hline$<10 \%$ & 3 & 4 & 3 & 8 & 4 & & & & & \\
\hline $10-50 \%$ & 11 & 3 & 6 & 3 & 3 & & & & & \\
\hline$>50 \%$ & 4 & 0 & 0 & 0 & 0 & & & & & \\
\hline
\end{tabular}




\begin{tabular}{|c|c|c|c|c|c|c|c|c|c|c|}
\hline Total $(n)$ & 18 & 7 & 9 & 11 & 7 & & & & & \\
\hline $\begin{array}{l}7 \text {. I usually reac } \\
\text { research team }\end{array}$ & ne lif & asses & pro & d b & & $0.214^{\mathrm{a}}$ & $0.025^{\mathrm{a}}$ & $0.090^{\mathrm{b}}$ & $0.001^{\mathrm{a}}$ & $0.055^{\mathrm{b}}$ \\
\hline Agree & 8 & 0 & 4 & 2 & 1 & & & & & \\
\hline Partly agree & 8 & 1 & 3 & 1 & 3 & & & & & \\
\hline Partly disagree & 1 & 4 & 2 & 3 & 2 & & & & & \\
\hline Disagree & 2 & 6 & 2 & 8 & 4 & & & & & \\
\hline Total $(n)$ & 19 & 11 & 11 & 14 & 10 & & & & & \\
\hline
\end{tabular}

${ }^{\mathrm{a}}$ Mann-Whitney $U$ test.

${ }^{\mathrm{b}}$ Kruskal-Wallis test.

${ }^{\mathrm{C} C h i-s q u a r e d ~ t e s t . ~}$

dOnly respondents who state they do refer to the CLT. 
Figure 1

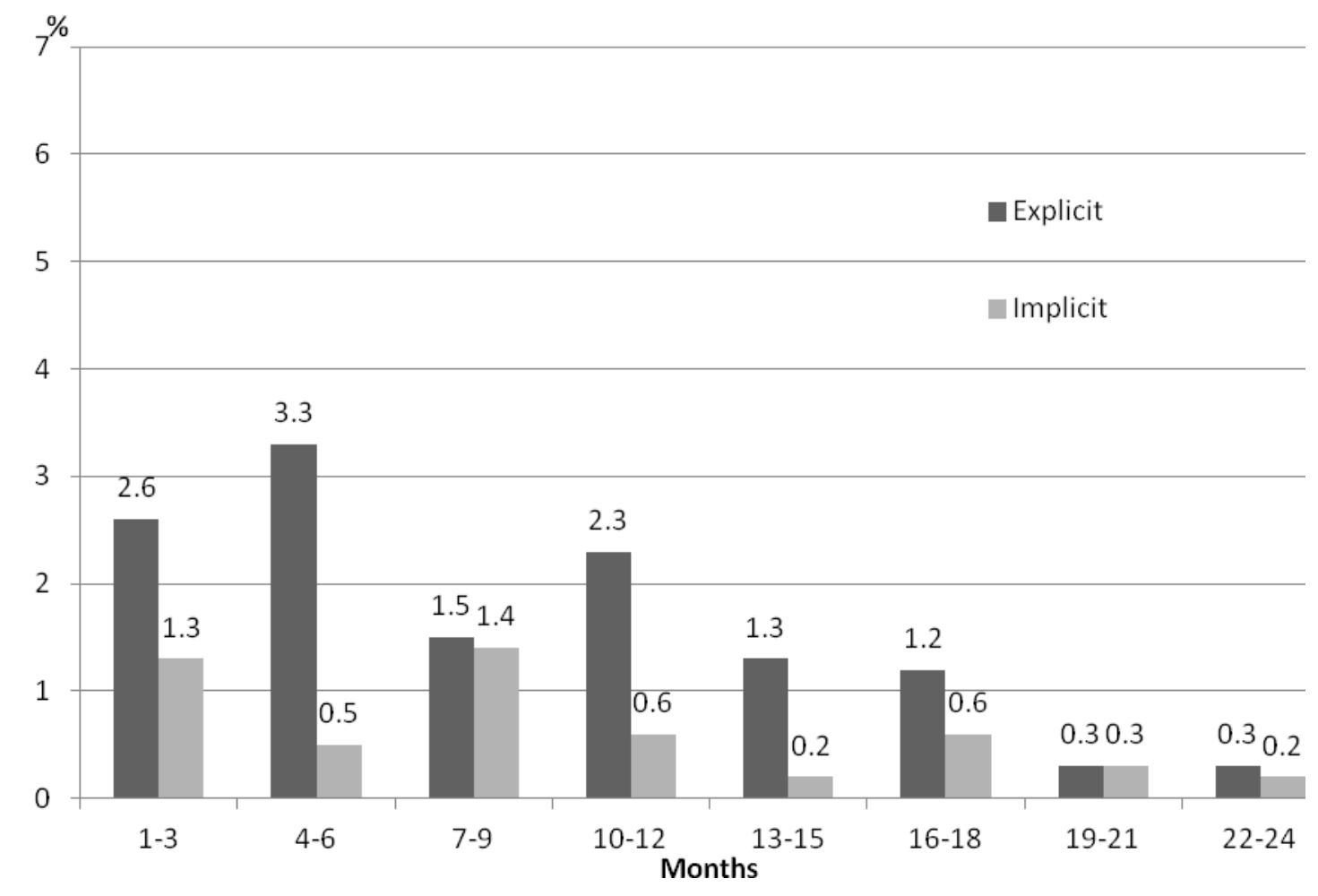


Figure 2

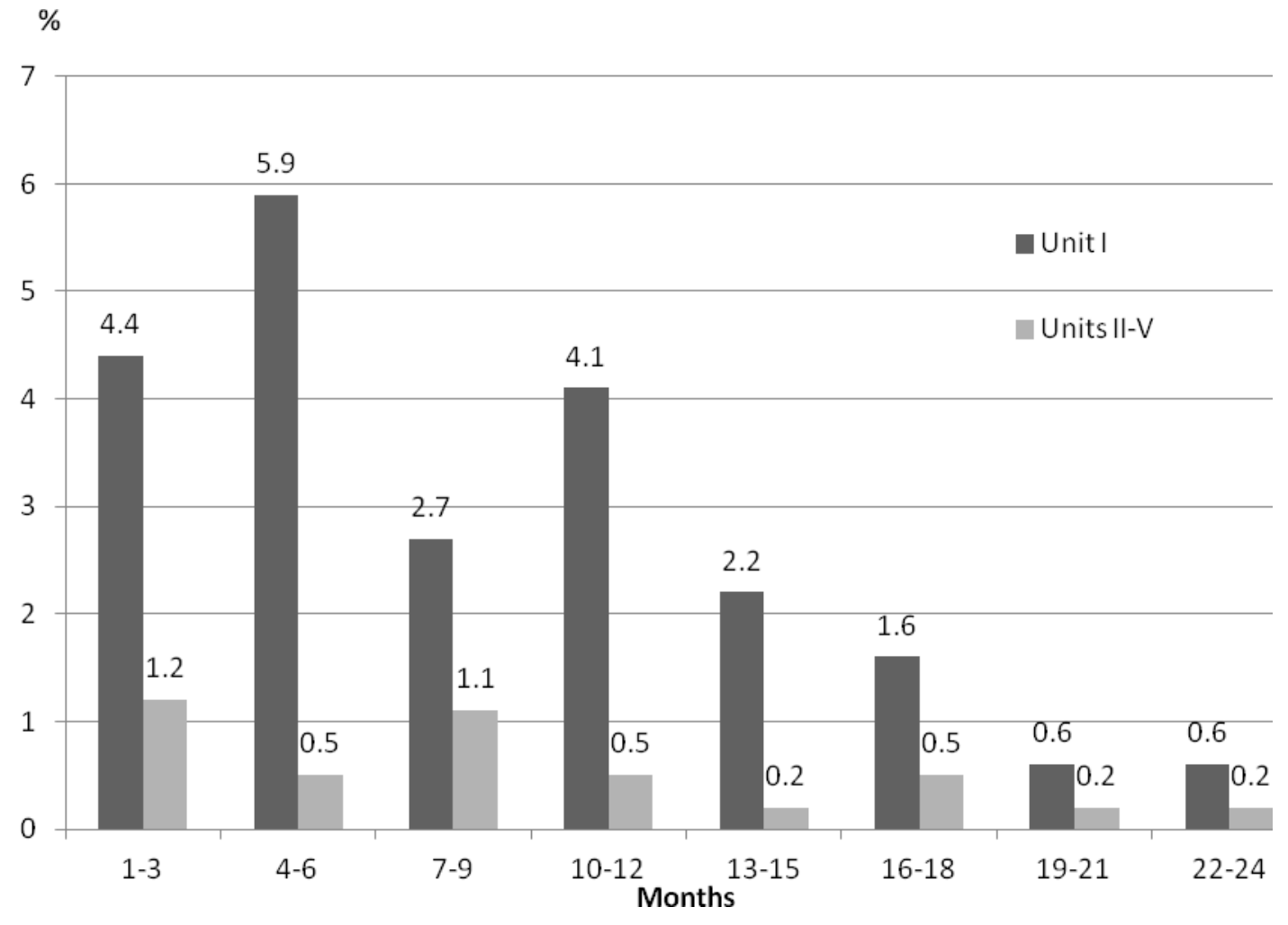

